\title{
A inter-incompreensão polêmica e sua versão solipsista em práticas de leitura emergentes
}

\section{La intercomprensión polémica y su versión solipsista en prácticas de lectura emergentes}

\section{The controversial inter-incomprehension and its solipsistic versión in emerging reading practices}

\author{
Manoel Luiz Gonçalves Corrêa ${ }^{1}$ \\ Universidade de São Paulo (Brasil) \\ $\underline{\text { mcorrea@usp.br }}$
}

Fecha de recepción: 19 de agosto de 2019

Fecha de recepción evaluador: 21 de agosto de 2019

Fecha de recepción corrección: 30 de agosto de2019

\begin{abstract}
Resumo
Neste trabalho lanço mão de três reflexões teóricas, advindas de três diferentes autores, para abordar e aproximar, em tom ensaístico, dois efeitos das tecnologias digitais de informação e comunicação (TDIC): por um lado, seu efeito em relação às práticas de leitura; e, por outro lado, seu papel quanto à universalização da informação aplicada à internacionalização dos produtos do conhecimento científico gerado pelas pesquisas

\footnotetext{
${ }^{1}$ Manoel Luiz Gonçalves Corrêa é professor sênior do Departamento de Letras Clássicas e Vernáculas da Faculdade de Filosofia, Letras e Ciências Humanas da Universidade de São Paulo (USP). Tem experiência na área de Linguística, com ênfase em Ensino de Português L1, atuando principalmente no estudo dos temas: escrita, letramento e discurso. https://orcid.org/0000-0003-3638-7086
} 
produzidas localmente em universidades e institutos de pesquisa. Num primeiro momento, lançando mão da ideia de inter-incompreensão polêmica (Maingueneau, 1987/1989), procuro definir - como um contraexemplo dessa noção - o que chamo leitura solipsista e ecumenismo solipsista. Em seguida, baseando-me na crítica de Foucault (1971/2004, pp. 45-51) à racionalidade imanente do pensamento ocidental, corroborada, a meu ver, pela ideia de acabamento por fechamento de Bakhtin (1979/1992, pp. 310311) comento um aspecto dessa crítica relacionando-a ao fenômeno da internacionalização da produção do conhecimento científico na forma atualmente propagada pelas universidades do mundo todo (e do Brasil, em particular). Ao final, a título de conclusão, procuro aproximar o ecumenismo solipsista e a uniformização dos modos de dizer no que se refere à produção de pesquisa.

Palavras-chave: leitura; leitura solipsista; ecumenismo solipsista; TDIC; internacionalização; imanentismo.

\title{
Resumen
}

En este trabajo tomo como punto de partida tres reflexiones teóricas, provenientes de tres autores diferentes, para abordar y presentar, a modo de ensayo, dos efectos de las tecnologías de la información y la comunicación (TIC): por un lado, su efecto en las prácticas de lectura y, por otro, su papel en relación a la universalización de la información aplicada a la internacionalización de los produtos del conocimiento científico generados por las investigaciones que se desarrollan localmente en universidades e institutos de investigación. En primer lugar, apoyándome en la idea de intercomprensión polémica (Maingueneau, 1987/1989), intento definir -como contraejemplo de esa noción- lo que denomino lectura solipsista y ecumenismo solipsista. A continuación, basándome en la crítica de Foucault (1971/2004, pp. 45-51) a la racionalidad inmanente del pensamiento occidental, que se corrobora, en mi opinión, con la idea de conclusividad del enunciado de Bakhtin (1979/1992, pp. 310-311), comento un aspecto de esa crítica y lo relaciono con el fenómeno de la internacionalización de la producción del conocimiento científico, tal como actualmente se propaga por las universidades de todo el mundo (y de Brasil, en particular). Por último y a modo de conclusión, ensayo un acercamiento entre el ecumenismo solipsista y la uniformización de los modos de decir relacionados con la producción de la investigación.

Palabras clave: lectura; lectura solipsista; ecumenismo solipsista; TIC; internacionalización; inmanentismo.

\begin{abstract}
I discuss three theoretical issues in this essay, coming from three different authors, to come nearer and approach two effects of the Digital Information and Communication Technologies (DICT): on one side, its effect regarding reading practices; on the other one, its role in relation to the generalization of information applied to making products coming from scientific knowledge international. That scientific knowledge is produced in researches carried out by universities and research institutes. At first, considering the idea
\end{abstract}


of the controversial inter-incomprehension (MAINGUENAU, 1987:1989), I intend to define - as a counterexample of that concept - what I call solipsistic reading and solipsistic ecumenism. Then, based on Foucault's criticism (1971:2004, p. 45-51) of the immanent rationality of the Western thought, reinforced, as I see it, by Bakhtin's idea (1979-1992, p. 310-311) of ending an utterance through a closure, I comment on an aspect of that criticism, relating it to the internationalization phenomenon of the scientific knowledge production in the universities of the whole world (particularly, in Brazil) nowadays. By the end, to sum up, I try to make the solipsistic ecumenism close to the standardization of the modes of saying related to the research production.

Keywords: reading; solipsistic reading; solipsistic ecumenism; DICT; internationalization, immanentism.

\section{Introdução}

Este trabalho apresenta um tom ensaístico, já que é produto de uma palestra (e não de um trabalho de pesquisa específico) proferida na XX Jornada Multidisciplinar "Comunicação, (des)ilusões e (des)afetos" do Departamento de Ciências Humanas da Faculdade de Arquitetura, Artes e Comunicação da Unesp de Bauru (São Paulo-Brasil), realizada nos dias 02 e 03 de setembro de 2018.

Parto de três reflexões teóricas diferentes, vindas de Maingueneau (1987/1989), Foucault (1971/2004) e Bakhtin (1979/1992), para abordar e aproximar dois efeitos das tecnologias digitais de informação e comunicação (TDIC). O primeiro desses efeitos tem relação com novas práticas de leitura e escrita e é tratado aqui do ponto de vista da leitura. O segundo tem relação com o aspecto da universalização da informação aplicada à internacionalização dos produtos do conhecimento científico gerado pelas pesquisas produzidas localmente em universidades e institutos de pesquisa.

O trabalho se organiza da seguinte maneira: num primeiro momento, recorrendo à ideia de inter-incompreensão polêmica (Maingueneau, 1987/1989), procuro definir como um contraexemplo dessa noção - o que chamo leitura solipsista e ecumenismo solipsista. Em seguida, baseando-me na crítica de Foucault (1971/2004, pp. 45-51) à racionalidade imanente do pensamento ocidental, corroborada, a meu ver, pela ideia de acabamento por fechamento de Bakhtin (1979/1992, pp. 310-311), comento um aspecto dessa crítica, relacionando-a ao fenômeno da internacionalização da produção do conhecimento científico na forma atualmente propagada pelas universidades do mundo todo (e do Brasil, em particular). Ao final, a título de conclusão, procuro aproximar o ecumenismo solipsista e a uniformização dos modos de dizer quando se trata da produção de pesquisa.

\section{A inter-incompreensão regrada de Maingueneau: sua contraversão no caso do ecumenismo solipsista em práticas de leitura e escrita emergentes}


Na primeira edição da Jornada Multidisciplinar, realizada entre 12 e 14 de maio de 1997, apresentei um trabalho com o título "A heterogeneidade cultural: um caso de inter-incompreensão regrada". Naquele momento, dirigia-me especialmente ao professor e ao comunicador, com a expectativa de alertar a um e a outro sobre o necessário trabalho com a heterogeneidade que constitui a língua e o discurso. $\mathrm{O}$ alerta procurava chamar a atenção para o direcionamento e a organização argumentativa dos textos, já que a construção do destinatário na organização argumentativa constitui o espaço polêmico em que se dá o fenômeno da inter-incompreensão regrada (Maingueneau, 1987/1989).

Buscava chamar a atenção, portanto, para o fato de que, quando se diz que "comunicação" corresponde a "tornar comum", não significa que comunicar corresponda sempre a unificar e homogeneizar os sentidos - visão que poderíamos chamar, em chave irônica, de visão ecumênica da linguagem. Se assim fosse, professor e comunicador, ao recorrerem a substituições de palavras menos usuais por outras mais "comuns", poderiam fiar-se na existência de uma "comunidade de sentido" homogênea e sem conflito, numa espécie de ecumenismo paradisíaco. No limite, nunca se pode chegar à facilitação com respeito ao potencial espaço polêmico que o uso de qualquer palavra pode ter, mesmo sendo ela muito comum (talvez até por isto mesmo!).

A crença na ideia de simplificação como estratégia para se aproximar do outro apresenta pelo menos dois aspectos. O primeiro é exequível - digamos - no jogo inconsciente/consciente da formulação do discurso, jogo que leva a certa escolha de palavras e construções. Naturalmente, esse é um argumento ligado à forma dos enunciados. $\mathrm{O}$ segundo aspecto dessa crença liga-se também ao propósito de agir sobre o outro e depende, tanto quanto o primeiro, das representações que a pessoa que fala/escreve faz sobre si mesma, sobre o outro e sobre aquilo que ela diz. No entanto, se o primeiro aspecto centraliza a solução no professor ou no comunicador, bastando a eles facilitar as escolhas vocabulares e a sintaxe para falar sobre as coisas; o segundo, centrado no outro, tem de eleger como finalidade a construção do acordo, fenômeno que, mesmo que provisório, se resolve apenas por utilizar a linguagem num registro palatável ao destinatário. É preciso, ao mesmo tempo, falar ao/falar o/ e falar com o destinatário.

Considerando-se que, nesse movimento, há espaço para réplicas por parte do destinatário - sejam elas imediatas, no modo de enunciação oral, sejam elas antecipadas pelo escrevente, na interlocução também sempre presente na enunciação escrita - e também para a reconfiguração da argumentação, pode-se dizer que, na busca de fazer sentido para o outro, instaura-se, com a interação, também a polêmica. No entanto, a relação mantida entre interlocutores em atos isolados, apesar de exemplificar, não explica todo o alcance da polêmica, que é mais bem-delimitado pelas noções de interdiscurso e de formação discursiva, as quais estão na base da produção de todo discurso.

Ao comentar a noção de interdiscurso, Maingueneau afirma que a polêmica está na base da constituição de uma formação discursiva. E citando Courtine e Marandin, diz: “o fechamento de uma formação discursiva é fundamentalmente instável, [...] uma 
fronteira que se desloca em função dos embates da luta ideológica" (Courtine \& Marandin cit. por Maingueneau, 1987/1989, p. 112, itálico no original).

Uma formação discursiva não é, portanto, definível por uma espécie de essência que constituiria o seu modo de regrar um discurso independentemente de qual(is)quer outra(s) formação(ões) discursiva(s). Para o autor, uma formação discursiva depende de sua relação com outras, sempre sustentada na polêmica.

Disso tudo, é importante destacar que a polêmica impõe, para todo discurso, um dialogismo constitutivo, embora nem sempre mostrado (Maingueneau, 1987/1989, p. 123).

Um exemplo interessante é o do "polemista" representado no quadrinho abaixo.
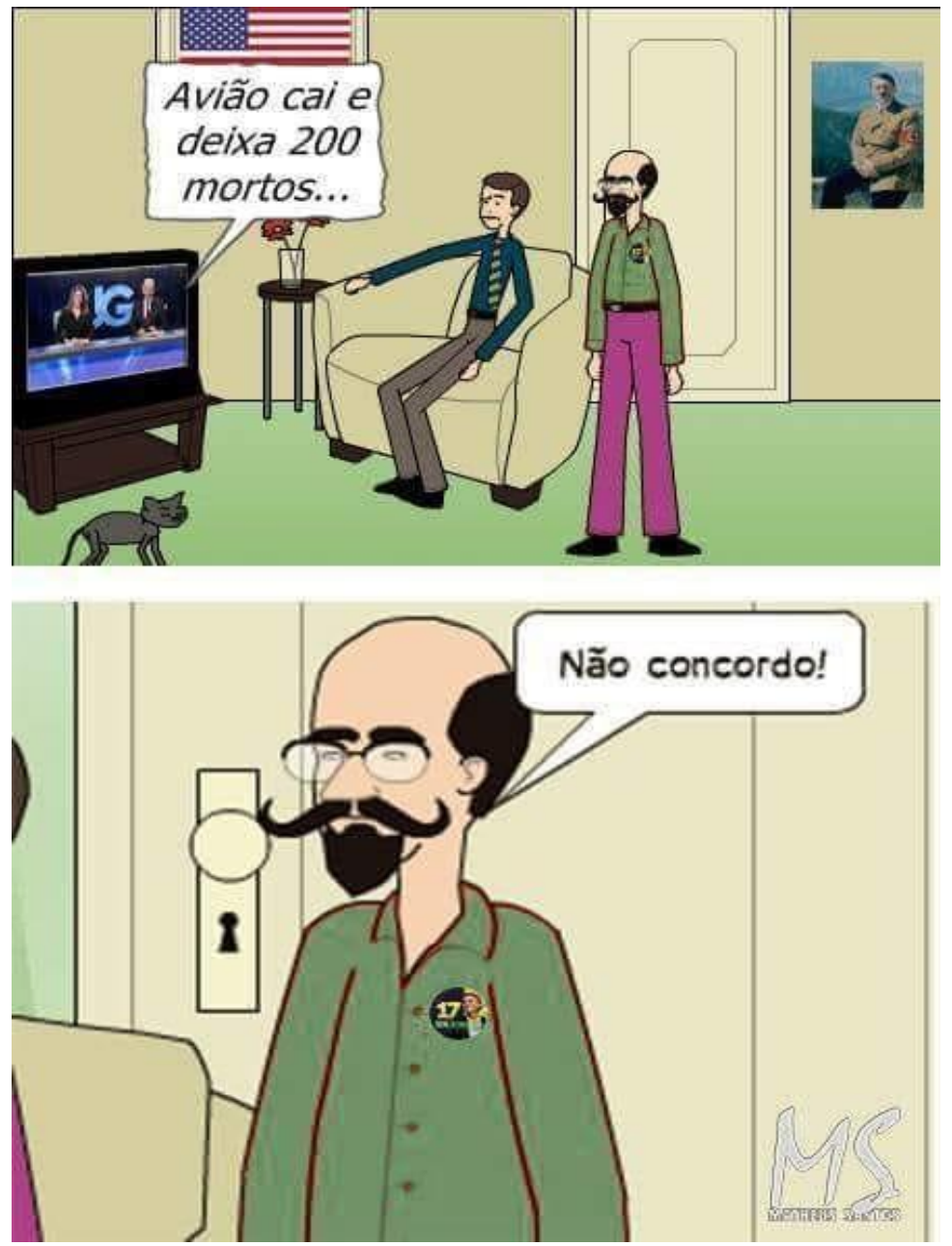

https://www.slideshare.net/charlleyluz/pos-verdade-e-a-informao ${ }^{i}$

Note-se que, mesmo quando se trata de um fato inconteste, a personagem não perde a chance de manifestar a sua discordância. Em casos como esse, pelo menos, duas leituras são possíveis.

Grosso modo, pode-se dizer que a alternância entre os dois enunciadores (que chamo de A e B): 
A - "Um avião cai e deixa 200 mortos..."

B - "Não concordo!"

pode ser interpretada, num primeiro momento, como caracterizando a personagem que retruca ao noticiário por seu desejo de afirmação da polêmica, mesmo em relação a uma notícia que não deixaria espaço para polemizar em termos de concordância ou discordância. Uma segunda interpretação seria, ao contrário, a de tomar o enunciado de B (“Não concordo!") como uma tentativa de negação da polêmica, já que desconsidera o dito - que não é sujeito à concordância ou discordância - para responder (e desqualificar) o seu autor. Num caso e no outro, é a discordância com algo não passível de réplica que cria o efeito de humor. Mas por que esse efeito é criado?

Naturalmente, não porque os produtores da notícia tenham sido desautorizados, nem porque o conteúdo do enunciado tenha sido invalidado de algum modo. Parece que o efeito ocorre em função da ruptura com uma regra mais geral, a da polêmica, como constitutiva do enunciado, que, por sua vez, sempre faz parte do discurso, também ele definido pela relação com outro(s) discurso(s). Nem o enunciado, nem o discurso que o abrange se fazem sem o dialogismo constitutivo (Maingueneau, 1987/1989, p. 123). Em outras palavras, se um discurso se caracteriza por uma formação discursiva que regula o seu aparecimento, é preciso lembrar que antes e aquém do discurso há o interdiscurso, no qual uma formação discursiva se define pela relação com outra(s). A configuração de um discurso pressupõe a primazia do interdiscurso, ou dito de outro modo, supõe relações interdiscursivas. Os discursos não se confundem, portanto, com o rótulo tipológico com que os nomeamos e os multiplicamos indefinidamente: discurso político, religioso, pedagógico, jurídico e outros. Constituem-se, ao contrário, no interior de um campo discursivo. Segundo Maingueneau, essa classificação tipológica não dá conta de explicar a conformação de um campo discursivo até pela razão de que as formações discursivas de um campo podem ir além das "grades grosseiras" (Maingueneau, 1987/1989, p. 117) dessa tipologia. Além disso, a própria regulação de uma formação discursiva atuante sobre o discurso é definida em função de sua relação com outras formações discursivas, de tal modo que o espaço de polêmica se constitui no que Maingueneau chama de espaço discursivo.

O que, no exemplo, é feito para fazer rir tem ocorrido, com frequência, no discurso cotidiano, mas de um modo um pouco diferente. No quadrinho, o telespectador replica ao assunto (um acidente de avião) por meio de uma manifestação imprópria de discordância, já que, nesse caso, o acidente, por ser constatável como um fato, não é suscetível de polêmica.

Por sua vez, nas redes sociais e na escola (mesmo no ensino superior), ocorrências semelhantes, já constituindo quase um padrão de leitura e, portanto, apresentando frequência significativa, têm o efeito de apagamento da presença do outro, fazendo aparecer uma versão solipsista de leitura por meio do apagamento da polêmica. Baseeime no dicionário para escolher essa denominação. No dicionário Aulete eletrônico, 


\section{(so.lip.sis.mo)}

sm.

1. Fil. Doutrina segundo a qual o eu empírico é a única realidade.

2. P.ext. Vida ou costumes de quem vive na solidão.

[F.: Do lat. solus, 'só', + ipse, 'mesmo', + -ismo.]

e no Houaiss eletrônico, temos:

solipsismo (1865 cf. Cort)

\section{substantivo masculino}

1 fil doutrina segundo a qual só existem, efetivamente, o eu e suas sensações, sendo os outros entes (seres humanos e objetos), como partícipes da única mente pensante, meras impressões sem existência própria [Embora freq. considerado uma possibilidade intelectual (caso limite da filosofia idealista), jamais foi endossado integralmente por algum pensador.]

2 p.ext. vida ou conjunto dos hábitos de um solipso (no sentido de 'solitário'; 'celibatário'; 'masturbador').

Dessas definições, basta reter a centralidade do eu que caracteriza a negação da polêmica a que estou me referindo.

Antes de prosseguir, vale lembrar que a versão solipsista que se define pelo apagamento da polêmica não altera - ainda a partir de Maingueneau - a realidade do dialogismo constitutivo (Maingueneau, 1987/1989, p. 123) de uma formação discursiva. Isto é, ela se realiza dialogicamente no interior de um dado campo e de um dado espaço discursivos. A polêmica é, pois, constitutiva dessas relações, mas nem sempre se configura, como ficou dito, em termos de um dialogismo mostrado (Maingueneau, 1987/1989, p. 123). Note-se, também, que o espaço discursivo é propriamente o espaço da polêmica, no qual entra em jogo não uma formação discursiva mas a interação entre formações discursivas (Maingueneau, 1987/1989, p. 119). Desse modo, segundo o autor, "a identidade discursiva está construída na relação com o Outro" (Maingueneau, 1987/1989, pp. 119-120).

Uma vez fixado que uma formação discursiva se estabelece na relação com outras, chegamos ao ponto de definir, com o autor, o fenômeno da inter-incompreensão, noção que orienta parte do que pretendo dizer:

Esta interação entre [pelo menos] dois discursos em posição de delimitação recíproca pode ser compreendida como um processo de "tradução" generalizada, ligada a uma "inter-incompreensão". Tradução de um tipo bem particular, entretanto, pois ela opera, não de uma língua natural para outra, mas de uma formação discursiva à outra, isto é, entre zonas da mesma língua. Isto faz justiça à linguagem comum, que lembra 
precisamente certos "diálogos de surdos" entre protagonistas que, no interior do mesmo idioma, "não falam a mesma língua. (Maingueneau, 1987/1989, p. 120)

Portanto, segundo Maingueneau, o fenômeno da inter-incompreensão "obedece a regras e estas regras são as mesmas que definem a identidade das formações discursivas consideradas" (Maingueneau, 1987/1989, p. 120).

Para voltar ao apagamento da polêmica, lembremo-nos de que, se em condições normais de uso da linguagem, os discursos se constituem da relação entre formações discursivas marcadas pela inter-incompreensão constitutiva, pode-se também concluir que a polêmica é um elemento central na produção de sentidos.

Ora, considerando que a polêmica pode ser recusada e que esse apagamento tem sido um dos procedimentos de leitura atestados no cotidiano das redes sociais e mesmo na leitura de textos na escola, o que restaria de sentido a ser produzido?

Duas possibilidades se apresentam: 1) atribuir a produção de sentido à dimensão da língua e da sociedade, tidas, porém, uma e outra, como produtoras de um sentido ecumênico, sem arestas nem conflitos, em que a polêmica se resolveria pelo "tornar comum"; 2) recolher-se ao ecumenismo solipsista do sujeito, que, posto no centro da linguagem, atribui aos outros, como vimos no sentido dicionarizado de solipsismo, o papel de partícipes da única mente pensante (a do próprio sujeito). $\mathrm{O}$ caso tratado neste ponto do trabalho não é, portanto, o do ecumenismo ligado à língua e à sociedade, cujo efeito nefasto seria o de apagar as diferenças tanto em relação a zonas particulares de produção de sentido a partir da língua quanto em relação à sociedade; efeito que faria pensar que os sentidos brotam, em ambas, de uma suposta comunidade homogênea e plena de compreensão. Pelo contrário, neste momento, trato do recolhimento ao paradoxal ecumenismo solipsista do sujeito. Ecumênico porque distribuído e generalizado, solipsista porque é próprio do sujeito que considera que a única realidade é

aquela reconhecida pelo seu eu. É, pois, desse ecumenismo que trato ao falar de leitura solipsista.

Neste ponto, encaminho a discussão segundo dois passos. O primeiro passo consiste de um comentário do que, criticamente, Foucault (1971/2004) chama de racionalidade imanente do pensamento ocidental, ideia à qual, ainda neste primeiro passo, associo uma contribuição de Bakhtin (1979/1992) e um aspecto que destaco das tecnologias digitais de informação e comunicação. O segundo passo consiste de um comentário sobre a política de internacionalização da produção de pesquisa e sua relação com o que se reteve de Foucault, Bakhtin e do aspecto destacado sobre as tecnologias digitais de informação e comunicação.

\section{A crítica de Foucault ao imanentismo do pensamento ocidental e o tema da internacionalização da produção de pesquisa}


Sintetizo, com alterações, nos três parágrafos seguintes, um capítulo de livro de minha autoria (Corrêa, 2018), em que, baseado em Foucault (1971/2004) e em Bakhtin (1979/1992), trato do imanentismo na produção de novas práticas de leitura e escrita e de novos gêneros do discurso no contexto das tecnologias digitais de informação e comunicação. Com base nessa síntese, trato, em seguida, da insistente chamada dos pesquisadores, ao menos na universidade brasileira da virada do século XX para o XXI, à internacionalização da produção de pesquisa, formulação que utilizo aqui para tratar o conhecimento como produto, como mercadoria.

Tomando, portanto, de Foucault a crítica à "racionalidade imanente do pensamento ocidental" (Foucault, 1971/2004, pp. 45-51), exploro o restrito lugar dado ao discurso, já que, segundo Foucault, a tônica dessa racionalidade é ligar pensamento e palavra de modo direto. Retomo essa crítica em vários momentos a seguir.

No que se refere a Bakhtin, destaco a ideia de acabamento segundo a distinção que o autor faz entre "oração" e "enunciado" (Bakhtin, 1979/1992, pp. 310-311). Afirma Bakhtin que o acabamento por fechamento que a oração apresenta na qualidade de unidade da língua não encontra correspondência no enunciado, cujo acabamento se dá por abertura, já que este tem a natureza do evento concreto, do fato discursivo, com acabamento sempre no outro. A ideia de acabamento também serviria para caracterizar o que Foucault (1971/2004, pp. 45-51) chama de racionalidade imanente do pensamento ocidental, já que, tendendo a rarefazer o discurso, é o acabamento por fechamento que nela se aplicaria.

Acrescente-se que o mecanismo próprio da racionalidade imanente do pensamento ocidental inclui, na atualidade, a participação das tecnologias digitais de informação e comunicação, aspecto ao qual me atenho neste ponto. Essa participação se dá não só pela nova relação com o tempo e com o espaço, que rompe fronteiras e cria o efeito de universalização, mas, em particular, pela instalação do novo. O intrigante desse efeito de racionalidade imanente é que ele se mostra não só pelo parto ininterrupto de novos recursos por parte das tecnologias digitais de informação e comunicação, mas também pelo fato de fazer crer que essas tecnologias são as reais produtoras do sentido (e do sentido novo, cuja novidade se associaria à novidade daqueles recursos, numa circularidade interna às próprias máquinas, constituídas por uma rede de conexões que tenderia ao infinito). O resultado é um sentido que se diz pelo ponto que ocupa nessa rede, num efeito drástico de rarefação do discurso, para usar uma outra expressão de Foucault (1971/2004). Desse modo, o sentido passa a ser visto como produto de uma rede de dados tecnológicos, numa pretensa suplantação da linguagem articulada, ou seja, da palavra dita e do dizer do sujeito.

Vale sempre lembrar, porém, que as semioses empregadas nessas tecnologias não são inéditas, já que derivam de combinações de semioses preexistentes. No campo da linguagem verbal, contra, por exemplo, a ideia de que gêneros do discurso absolutamente inéditos surgiriam dos recursos tecnológicos, constata-se que, mesmo aqueles tidos como novos, são produto da relação entre gêneros preexistentesii e resultantes do trabalho 
humano com as diversas semioses. No entanto, tudo se passa como se, na produtividade tecnológica - resultante do trabalho científico que se concretiza na produção de autômatos -, os dispositivos lógicos utilizados para resolver algoritmos conduzissem à produção de semioses e gêneros genuinamente digitais. Uma vez mais, apaga-se o fazer particular de quem produz e de quem se utiliza dessas semioses e desses gêneros, ou seja, privilegiase o recurso tecnológico à produção do sentido no discurso. Em outras palavras, atribuise o sentido não ao discurso, em que há sujeitos se relacionando em tempos e espaços determinados, mas ao próprio recurso tecnológico, o qual, obviamente, participa da produção de efeitos de sentido e de certo cálculo do sentido - penso, por exemplo, na (im)precisão do sentido quando interpretamos a conformação dos caminhos calculados pelos aparelhos de GPS -, o que não autoriza a vê-lo como produtor do sentido. Quando posta nesta última posição, a máquina passa a ocupar o lugar de responsável pelo sentido, o que corrobora, uma vez mais, a crítica de Foucault à racionalidade imanente do pensamento ocidental que consiste em rarefazer o discurso, neste caso atribuindo-o à própria máquina, com base no esquecimento de quem a produz/programa e de quem a utiliza.

Feitas essas observações, encerro esta parte do trabalho, buscando abordar uma questão candente que, a meu ver, reproduz o imanentismo criticado por Foucault. Tratase do tema da internacionalização da produção de pesquisa.

No caso da internacionalização da produção de pesquisa, não se pode escapar do fato de que é sempre num âmbito local que o conhecimento é produzido. Pode-se, pois, pensar em particularidades do discurso científico segundo a língua e o local de sua produção. No entanto, ao se contrapor o caráter local da produção a um suposto caráter global, configura-se, neste segundo polo, uma produção não situada, válida globalmente, numa adesão à ideia de um discurso científico universalizado, dotado de uma língua específica, o inglês. A internacionalização da produção de conhecimento não se atém, portanto, apenas à sua divulgação, mas, antes dela, a uma sua adaptação àquele modo global, tido como não situado, de produção do conhecimento, no sentido de alcançar o modo apropriado do padrão "global" de produção, espécie de discurso científico validado como uma língua própria do conhecimento. Nesse embate, a produção local passa a ser uma adaptação a esse padrão global, com reduzidas chances de reciprocidade. $\mathrm{O}$ efeito de transformação limita-se, assim, a um dos polos. Lillis $(2003$; 2008) destaca que, nessa passagem, há uma questão ligada à língua. Não se trataria, portanto, de uma simples operação adaptativa ao texto científico dotado de um padrão apátrida. Expressar-se de um modo científico exigiria modos de dizer particulares da língua tida como língua da ciência, o inglês, o que impõe restrições ao que é expresso nas línguas locais (supostos excessos e imprecisões, mas, de fato, frequentemente fragmentos que marcam importantes modalizações do sujeito) e em seus modos de expressar a sua produção científica. Ainda a partir de Foucault (1971/2004, pp. 13-21), uma tal restrição a modos de dizer poderia ser incluída como traço da racionalidade imanente do pensamento ocidental e, no caso da chamada internacionalização da produção de conhecimento, também como servidão a uma vontade de verdade que não teria nada de imanente, já que é sempre historicamente determinada. 
O trabalho de passagem dos modos de dizer locais para o modo de dizer global seria, ainda, a meu ver, um caso de acabamento por fechamento. Em outras palavras, lidando com discursos que se abrem para o aspecto histórico do que é situado, o requisito central dessa passagem é, numa outra direção, o de tornar-se um exemplar do discurso científico segundo modos de dizer de uma dada língua, tomada como representante desse discurso. Portanto, aquilo que deveria abrir-se como identidade própria para a internacionalização se produz, paradoxalmente, como unidade de uma rede, abdicando das cores locais em favor de um modo de dizer apenas supostamente não situado, o de uma língua, com todas as consequências linguísticas, cognitivas e culturais dessa passagem.

\section{Ler e escrever é sempre junto com o outro}

Em dois momentos deste trabalho, tomei as tecnologias digitais de informação e comunicação como participantes de dois fenômenos relacionados ao sentido e às (des)ilusões quanto à comunicação, inclusive à comunicação ligada à produção de pesquisa e de conhecimento científico.

Num primeiro momento, destaquei, no âmbito dessas tecnologias, o que chamo leitura solipsista, autocentramento máximo na interpretação do texto, caracterizando uma prática de não afetação pelo que se lê e pelo que se ouve, generalizada nas redes sociais, mas também atestada já na leitura praticada na escola. A observação dessa distribuição mais ou menos generalizada da leitura solipsista me levou a cunhar a expressão "ecumenismo solipsista" para me referir a uma prática que parece ganhar espaço na medida em que o indivíduo, produzido como consumidor de certezas, dessemiotiza a partilha dos signos, deixando escapar a polêmica, para reinvesti-los do mesmo que ele atribui só a si, ficando a diferença e a alteridade como sobras descartadas. Nesse caso, a leitura é o próprio sujeito solipsista e o trabalho semiótico dessa comunidade de sujeitos se relaciona com o signo, ecumenicamente, mas cada um por si, num reinvestimento do mesmo que - vale repetir - cada um se atribui só a si: o outro está lá, mas para reproduzir, também ele, indefinidamente, o ecumenismo solipsista. Ou seja, está lá como fenômeno, mas não como prática, o que permite o trabalho de esquiva quanto à inter-incompreensão constitutiva, deixando vazio o espaço discursivo (Maingueneau, 1987/1989), onde se dá a polêmica. A expressão de Bakhtin comentada acima parece aplicar-se muito bem aqui: na leitura e no ecumenismo solipsistas o que conta é o acabamento (do sentido) por fechamento (no próprio indivíduo), pois o discurso é amplamente desconsiderado.

Num segundo momento, destaquei o papel das tecnologias digitais de informação e comunicação na caracterização do imanentismo no momento mais importante do processo de conhecimento, o da sua partilha, tomada, aqui, na internacionalização da produção científica local. Como ficou dito, é a adaptação a uma língua representativa da ciência, ao seu caráter supostamente não situado, que conta neste caso. A comunicação entendida como "tornar comum" retorna com toda força. O ecumenismo linguístico, tomado como motor da compreensão plena, apaga especificidades (que são tomadas como defeitos) e modalizações (que são tomadas como interferências aproximativas do 
sujeito num assunto - a ciência - em que o distanciamento entre sujeito e objeto seria (?) o padrão). O caráter local é dito por modos não locais de dizer. A racionalidade imanente do pensamento ocidental impera sobre as particularidades das descobertas e dos descobridores. Paralelamente ao apagamento das marcas de sua produção, trabalhos escritos, artefatos ou projetos de intervenção (artística, material ou virtual) no mundo convertem-se em mercadorias, das quais talvez a mais intrigante é o próprio texto produzido pelo pesquisador, que, em certos casos, uma vez publicado, terá seu acesso cobrado até mesmo do seu próprio autor. O pesquisador e o operário se encontram, mesmo que nunca dividam o mesmo espaço.

Cabe, para encerrar, uma última observação sobre as tecnologias digitais de informação e comunicação e sua relação com a leitura solipsista e com a racionalidade imanente do pensamento ocidental. Nos dois casos, as tecnologias atuam como um recurso de universalização dos dizeres. Também nos dois casos, pode-se observar o desejo de protagonismo, ora no campo da leitura, ora no campo da produção do texto. No campo da leitura, é o sujeito que se candidata a ser o centro e ter a palavra final. No campo da produção do texto (em particular, do texto acadêmico-científico), é a produção local que se apresenta para expor, se possível de forma irrefutável, seu desempenho em âmbito global.

Como acredito ter deixado claro, não há, porém, em nenhum dos dois casos, centralidade nesses protagonismos. O leitor solipsista, ao negar a regra da interincompreensão constitutiva e, portanto, a polêmica entre formações discursivas, recolhese na tentativa de apagamento de toda exterioridade, do estranho, mas, ao inundar de mesmidade o seu território, acaba por se proteger no mesmo, no conhecido, isto é, pressupõe-se como igual a (outrem). Fora do dito, o mesmo é dominado por um préconstruído ${ }^{4}$ que equaciona (põe em relação de igualdade) o dizer de um e o dizer de outrem, sobre o qual a única intervenção é a sua assunção - mesmo no caso de sua negação, é à sua existência que se replica. O território ocupado pelo mesmo, pelo que é conhecido, onde costuma refugiar-se o solipsista (e a leitura solipsista) é, pois, justamente aquele em que o outro se mostra de forma mais contundente.

Um movimento inverso parece acontecer no caso da internacionalização dos produtos de pesquisa. Em contraste com o solipsista, é a diferença que se busca, tomandose, desta vez, o outro como medida, um modo de dizer que está alhures (acima?) e ao qual o pesquisador deve alçar-se. O produto, que seria a produção local de conhecimento internacionalizada, pode, no entanto, já não ser local. Não, naturalmente, por correr o risco de perder qualquer espécie de pureza enraizada numa ideia qualquer de cultura (científica ou outra) genuína, mas por não conter as precisões e as modalizações que a tradução para o modo de dizer tido como não situado impõe cortar. Portanto, do mesmo ao diferente, não há saída sem a consideração do outro. Não há apagamentos possíveis que resultem na centralidade do eu solipsista (ou na pureza do resultado científico produzido localmente), nem, tampouco, que justifiquem o abandono ao outro, ao estranho, ao estrangeiro (ou, no caso do leitor, à leitura institucionalizada como correta, 
forma de escapar da leitura solipsista, que, pelo fechamento a um padrão, apaga, também, a livre relação com o outro).

\section{Referências}

Abaurre, M. B. M., Fiad, R. S. \& Mayrink-Sabinson, M. L. (1997). Cenas de aquisição da escrita. Campinas: Mercado de Letras/Associação de Leitura do Brasil (ABL).

Abaurre, M. B. M., Fiad, R. S. \& Mayrink-Sabinson, M. L (Eds.). (2003). Estilo e gênero na aquisição da escrita. Campinas: Komedi.

Assis, J. A., Silva, J. Q. G. \& Lopes, M. A. P. T. (2015). Diálogos, interfaces e desafios em estudos sobre a linguagem em ação. Scripta, 19, pp. 1-18. Disponível em periodicos.pucminas.br/index.php/scripta/article/download/11298/9433.

Bakhtin, M. (1992). Estética da criação verbal (M. E. G. G. Pereira, trad., M. Appenzeller, rev.). São Paulo: Martins Fontes (Trabalho original publicado em 1979). Corrêa, M. L. G. Letramentos e gêneros do discurso na universidade. Incluindo discussão sobre (novas) práticas de leitura e escrita na internet. Em: Abreu-Tardelli, L. \& Komesu, F. (Eds.). (2018). Letramento e gêneros: aproximações, distanciamentos (pp. 108-126). Belo Horizonte: Editora PUC-Minas.

Courtine, J-J. (2016). Definição de orientações teóricas e construção de procedimentos em Análise do Discurso. (F.C. de Souza; M. L.A. da Silva, trad.). Policromias: revista de estudos do discurso, imagem e som, v. 1, pp. 14-35. Disponível em https://revistas.ufrj.br/index.php/policromias/issue/view/355/showToc (Trabalho original publicado em 1982).

Courtine, J.-J. (2014). Análise do discurso político: o discurso comunista endereçado aos cristãos. São Carlos: EdUFSCAR (Trabalho original publicado em 1981). Courtine, J.-J. \& Marandin, J.-M. Quel objet pour lanalyse du discours? Em: Conein, B. et. al. (Eds.). (1981). Matérialités discursives (p. 21-33). Lille: Presses Universitaires de Lille, 1981.

Faraco, C. A (2005). Autor e autoria. Em: Brait, B. (Ed.) Bakhtin: conceitos-chave (pp. 37- 60). São Paulo: Contexto.

Foucault, M. (2004). A ordem do discurso. São Paulo: Loyola (Trabalho original publicado em 1971).

Halbwachs, M. (1990). A memória coletiva. São Paulo: Edições Vértice/Editora Revista dos Tribunais Ltda. (Trabalho original publicado em 1950).

Komesu, F. \& Tenani, L. (2005). O internetês na escola. São Paulo: Cortez Editora.

Lea, M. R. \& Street, B. V. (2006). The "Academic Literacies" model: theory and applications. Theory into practice, 45(4), pp. 368-377. 
Lillis, T. (2003). Student wrtting as 'Academic Literacies': drawing on Bakhtin to move from critique to design. Language and Education, 17(3), pp. 192-207. Disponível em http://www.writing.ucsb.edu/wrconf08/Pdf Articles/Lillis Article2.pdf.

Lillis, T. (2008). Ethnography as method, methodology, and "Deep Theorizing": closing de gap between text and context in Academic Writing Research. Written Communication. 25(3), pp. 353-388. Disponível em: http://wcx.sagepub.com/content/25/3/353.abstract.

Maingueneau, D. (1989). Novas tendências em análise do discurso. Campinas: Pontes (Trabalho original publicado em 1987). Pêcheux, M. (1999). Papel da memória. Em: ACHARD, P. et al. Papel da memória (pp. 49-58). Campinas: Pontes (Trabalho original publicado em 1983).

Rojo, R. \& Moura, E. (Eds.). (2012). Multiletramentos na escola. São Paulo: Parábola.

\section{Notas}

1 O quadrinho existe na internet em, pelo menos, duas versões: a dos eleitores do atual presidente do Brasil Jair Messias Bolsonaro e a dos eleitores do Partido dos Trabalhadores. A versão apresentada aqui é a dos eleitores do Partido dos Trabalhadores. Observe-se que o personagem que se nega a concordar veste uma camisa em cujo bolso aparece a foto de Bolsonaro. Todo o cenário (bandeira dos Estados Unidos da América, foto de Hitler) é composto para caracterizar a postura conservadora do personagem de modo a ridicularizar aquele que se nega a dialogar. Na versão bolsonarista, é o símbolo do PT que está no bolso da camisa do personagem, compondo, com a bandeira da China e com a foto de Che Guevara, o personagem do extremista que se negaria a dialogar. Conferir esta última versão em: https://ptbr.facebook.com/CanalDaDireita/photos/dialogando-com-petistas-só-que-não/1433961730081687/

2 Pense-se, por exemplo, na mensagem eletrônica enviada por e-mail, hoje já em franco declínio no quesito "comunicação rápida" se comparada a outros meios. Num primeiro momento, a novidade da comunicação rápida a distância pode ter levado a pensar num gênero do discurso inteiramente novo, produzido com base na escrita. Note-se, porém, que a novidade estava no tempo gasto da produção à recepção e na agilidade para vencer espaços, atravessando um país ou um continente em curto intervalo de tempo. No entanto, observando os gêneros com os quais a mensagem eletrônica pode se relacionar, ela se constitui, de fato, na relação entre gêneros preexistentes, sejam eles gêneros escritos (ora mais formais como cartas comerciais ou ofícios, ora mais informais, como bilhetes - dentre outros), sejam gêneros falados (ora mais formais, como uma exposição oral, ora mais informais, como a própria conversação face a face - dentre outros). A propósito, essas combinações não são sequer privativas do recurso tecnológico, já que também podem aparecer fora das tecnologias digitais de informação e comunicação.

3. Na formulação de Courtine (1982/2016, p. 19), os elementos pré-construídos produzidos no exterior [de uma formação discursiva] são "interiorizados", isto é, acolhidos, absorvidos, reconfigurados ou, ao contrário, negados, ou mesmo ignorados (grifo meu). 